\title{
The influence of adipocyte-derived stem cells (ASCs) on the ischemic epigastric flap survival in diabetic rats
}

\author{
Cristina Pires Camargo ${ }^{1}$ (D), Marcia Saldanha Kubrusly ${ }^{2}$ (D), Julio Morais-Besteiro ${ }^{3}$ (D), Martim \\ Conrad Harmsen ${ }^{4}$, , Rolf Gemperli ${ }^{5}$ (D)
}

1. PhD. Discipline of Plastic Surgery - Microsurgical and Plastic Surgery Laboratory (LIM-04) - School of Medicine - Universidade de São Paulo (USP) Sao Paulo (SP), Brazil.

2. PhD. Liver Surgery Transplant Laboratory (LIM-37) - School of Medicine - Universidade de São Paulo (USP) - Sao Paulo (SP), Brazil.

3. PhD. Discipline of Plastic Surgery - Microsurgical and Plastic Surgery Laboratory (LIM-04) - School of Medicine - Universidade de São Paulo (USP) Sao Paulo (SP), Brazil.

4. PhD. Department of Pathology and Medical Biology - University Medical Center Groningen - University of Groningen - Groningen, Netherlands.

5. Full Professor and Head. Plastic Surgery Division - Discipline of Plastic Surgery - Microsurgical and Plastic Surgery Laboratory (LIM-04) - School of Medicine - Universidade de São Paulo (USP) - Sao Paulo (SP), Brazil.

\begin{abstract}
Purpose: To assess the effects of adipocyte-derived stem cell (ASC)-injection on the survival of surgical flaps under ischemia in diabetic rats. Methods: Diabetes was induced in 30 male Wistar rats using streptozotocin $(55 \mathrm{mg} / \mathrm{kg}$ ). After eight weeks, epigastric flap (EF) surgery was performed. The animals were divided into control (CG), medium-solution (MG), and ASC groups. The outcomes were: the survival area (SA), the survival/total area rate (S/TR), and expression levels (EL) of genes: C5ar1, Icam1, Nos2, Vegf-a. Results: In the ASC group, compared to CG, we observed improved flap SA (CG-420 $\mathrm{mm}^{2}$ vs. ASC-720 $\mathrm{mm}^{2} ; \mathrm{p}=0.003$ ) was observed. The S/TR analysis was larger in the ASC group (78\%) than the CG (45\%). This study showed an increase in the Vegf-a EL in the ASC group (2.3) vs. CG (0.93, $p=0.0008)$. The Nos2 EL increased four-fold in the ASC group compared to CG, and C5ar1 EL decreased almost two-fold in the ASC group vs. the CG ( $p=0.02)$. There was no difference among the groups regarding Icam1 EL. Compared to the MG, the ASC group had a bigger flap SA $\left(720 \mathrm{~mm}^{2}\right.$ vs. $301 \mathrm{~mm}^{2}$, respectively), a bigger S/TR (78\% vs. 32\%, $p=0.06$, respectively) and increased EL of Vegf-a (2.3 vs. 1.3, respectively). No difference between ASC-group and MG was seen regarding Nos2 $(p=0.08)$ and C5ar1 $(p=0.05)$. Conclusion: This study suggests that ASCs increase the survival of EF under IR in diabetic rats.
\end{abstract}

Key words: Diabetes. Ischemia. Surgical Flaps. Mesenchymal Stem Cells. Rats.

*Corresponding author: consultoriodracristina@gmail.com | (55 99) 9999-9999

Received: May 23, 2021 | Review: July 25, 2021 | Accepted: Aug 21, 2021

Conflict of interest: Nothing to declare.

Research performed at Microsurgical and Plastic Surgery Laboratory (LIM-04), School of Medicine, Universidade de São Paulo (USP), Sao Paulo-SP, Brazil. 


\section{Introduction}

Several strategies have been developed to increase flap survival in patients with diabetes, e.g., VEGF-a to stimulate neoangiogenesis ${ }^{1}$, and vasodilators ${ }^{2}$ and hyperbaric oxygen therapy to increase the oxygen supply ${ }^{3}$. However, these therapies have shown uncertain outcomes, because the necrosis may have multifactorial origin ${ }^{2,3}$.

In this sense, the use of stem cells in regenerative therapies can be an alternative $e^{4,5}$.

Mesenchymal cells can modulate inflammation (paracrine effect) and promote cell proliferation in injured tissues ${ }^{6}$.

Among mesenchymal stem cells, adipocyte-derived stem cells (ASCs) appear most promising, due to their low invasive harvesting and the possibility of collecting these in large quantities of liposuction ${ }^{6-9}$.

However, there is a lack of data related to the effects of ASCs on IR-induced tissue damage in diabetes.

Diabetes induces a pro-inflammatory state in the body. This activates the inflammation-related inducible nitric oxide synthase (Nos2) and causes uncoupling of the physiological NO balance. Inflammation renders vascular endothelial cells more adhesive to leukocytes through upregulation of intercellular adhesion molecule 1(ICAM-1). In diabetics, this endothelial dysfunction therefore also inhibits necessary angiogenic processes, that would augment tissue perfusion and wound healing. The administration of ASCs seems promising, because they act as a double-edged sword (immunomodulation and angiogenesis) ${ }^{10-13}$.

For this reason, this study aimed to evaluate the effects of ASCs on the survival of ischemic axial flaps in diabetic rats.

\section{Methods}

This study was approved by the Ethical Committee of the School of Medicine, Universidade de São Paulo (050/16). All animal management was in accordance with the International Council for Laboratory Animal Science.

We analyzed 30 isogenic male Wistar rats weighting 250-300 g. The animals were kept in a vivarium on a 12-h day/night cycle and fed standard feed and water ad libitum.

\section{Diabetes induction}

Streptozotocin (streptozotocin mixed anomers 031M1287V; Sigma-Aldrich, St. Louis, MO, USA) was injected (single dose) via the penile vein at a dosage of $55 \mathrm{mg} / \mathrm{kg}$ diluted in PBS $(\mathrm{pH}=7)$ under inhalation anesthesia $(20 \%$ isoflurane; $150-200 \mathrm{~mL} / \mathrm{min}$ ). Serum glucose levels were measured $24 \mathrm{~h}$ after the injections to confirm induction of diabetes (glycemia > $200 \mathrm{mg} / \mathrm{dL}$ ). Afterwards, all animals were maintained for 8 weeks without any treatment (insulin injection), and had the glycemic level (mean $521 \mathrm{mg} / \mathrm{dL}$ ) measured before receiving surgery.

\section{Harvesting and expanding ASC}

Three male Wistar rats, weighting 220-250 g, 8 weeks old, were used in this procedure. The rats were anesthetized by intraperitoneal injection of ketamine $(100 \mathrm{mg} / \mathrm{kg})$ and xylazine $(5 \mathrm{mg} / \mathrm{kg})$. Both inguinal regions were trichotomized, and topical chlorhexidine was applied for antisepsis. An oblique $1.5 \mathrm{~cm}$ incision along the inguinal region was made. The panniculus carnosus was dissected, and adipose tissues near the femoral and inferior vessels were dissected. The fat was placed in PBS solution and washed three times to remove blood and debris. It was cut using iris scissors and tweezers, and the pieces $(<1 \mathrm{~mm})$ were enzymatically dissociated for $30 \mathrm{~min}$ at $37^{\circ} \mathrm{C}$ in $0.1 \%$ trypsin/EDTA (Sigma-Aldrich). The trypsin was then inactivated by $10 \mathrm{~mL}$ of Dulbecco's modified Eagle's Medium (DMEM) supplemented with $10 \%$ fetal bovine serum (FBS) and $1 \%$ penicillin and erythromycin.

The digested material was centrifuged at $363 \mathrm{~g}$ for $5 \mathrm{~min}$ at $20^{\circ} \mathrm{C}$ to obtain cell pellets. The supernatant was carefully removed with a Pasteur pipette. The pellets were washed with $10 \mathrm{~mL}$ of DMEM.

After centrifugation, the supernatant was discarded and the pellet resuspended in $2 \mathrm{~mL}$ of DMEM, and $10 \mu \mathrm{L}$ of the suspension was used to determine cell survival by counting in a Neubauer chamber after staining with $0.4 \%$ trypan blue dye.

The cell suspensions were adjusted to $5 \mathrm{~mL}$, placed in $25 \mathrm{~cm}^{2}$ tissue culture flasks, and stored in a culture incubator under a humid atmosphere containing $5 \% \mathrm{CO}_{2}$ at $37^{\circ} \mathrm{C}$. Cells were passaged at $>80 \%$ confluence. An enzymatic dissociation method with $0.25 \%$ trypsin/EDTA in PBS for $2 \mathrm{~min}$ at $37^{\circ} \mathrm{C}$ was used to detach cells from the culture bottles (1:3 ratio). The cells were expanded (1:3) to passage 4 and frozen in liquid nitrogen.

For cell freezing, the culture medium was removed, and enzymatic digestion was performed with $0.25 \%$ trypsin/EDTA for $2 \mathrm{~min}$ at $37^{\circ} \mathrm{C}$. Digestion was terminated with DMEM supplemented with $10 \% \mathrm{FBS}$, and the cell suspensions were centrifuged at $1,800 \mathrm{rpm}$ for $5 \mathrm{~min}$. The resulting cell pellets were washed twice with DMEM. After the supernatant was discarded, the pellets were resuspended in $2 \mathrm{~mL}$ of $10 \%$ FCS for cell counting in a Neubauer chamber and subsequent calculation for a final concentration of $1 \times 10^{6}$ cells $/ \mathrm{mL}$ in PBS in cryogenic tube. After this procedure, we confirmed the cell viability and mesenchymal nature by flow cytometry ${ }^{14}$. 


\section{Surgical and ischemia/reperfusion procedures}

All animals were anesthetized with intraperitoneal injections of $100 \mathrm{mg} / \mathrm{kg}$ ketamine hydrochloride (Ketalar ${ }^{\circledR}$; Parke Davis, Detroit, MI, USA) and $15 \mathrm{mg} / \mathrm{Kg}$ xylazine (Rompun ${ }^{\circledR} 2 \%$; Bayer, Leverkusen, Germany). The ventral face of the abdomen was trichotomized. A $6 \times 3-\mathrm{cm}$ flap based on the inferior epigastric pedicle (IEP) was designed (Fig. 1). The flap was harvested, and a vascular clamp was applied in the IEP for $3 \mathrm{~h}$.

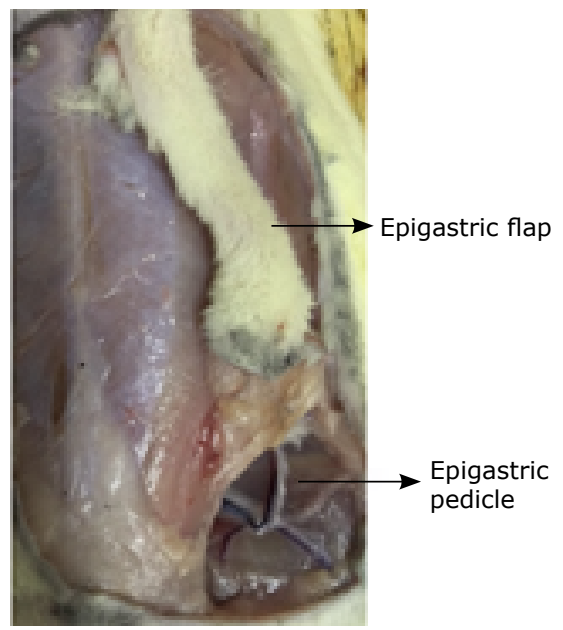

Figure 1 - Epigastric pedicle and surgical flap.

The vascular clamp was released, and $1 \mathrm{~mL}$ of mediumsolution (MG) or ASC $\left(1 \times 10^{6}\right.$ cells) was injected subcutaneously according to group allocation. The flap in the original location was sutured using mononylon 4-0 (Ethicon ${ }^{\circledR}, \mathrm{J} \&$, United States).

After the surgical procedure, the animals were then allocated into three groups:

- Control group (CG) $(n=10)$;

- Medium-solution group (MG - DMEM supplemented

with $10 \%$ FBS) (i.e., without ASC) $(n=10)$;

- ASC group (ASC) ( $n=10)$.

\section{Analysis of the survival area and survival area/ total area rate}

On the seventh postoperative day, all animals were euthanized by anesthetic overdose.

All flaps were photographed along with a centimeter ruler. The images were transferred to Image ${ }^{\oplus 15}$, and the total and survival areas $\left(\mathrm{mm}^{2}\right)$ were measured. These data were entered into a Microsoft Excel ${ }^{\otimes}$ (Microsoft Corporation, Redmond, WA, USA) spreadsheet, and the ratios of survival to total area were calculated.

\section{Microscopic analysis}

We collected a stripe of tissue $(0.5-\mathrm{cm}$ wide in the longitudinal axis of the flap). This sample was immersed in $4 \%$ neutral, phosphate buffered, paraformaldehyde, for $48 \mathrm{~h}$ at room temperature.

Tissue was washed, dehydrated in graded concentrations of alcohol, and embedded in paraffin. Four-micrometerthick sections were mounted on glass slides and stained with hematoxylin-eosin (HE). The sections were analyzed under the light microscope Nikon Optiphot-2 (Nikon, Tokyo, Japan), coupled to a Nikon DXM $1200 \mathrm{~F}^{\circledR}$ (Nikon, Tokyo, Japan) video digital camera. Measurements were performed using the Image ${ }^{\circledR}$ (Media Cybernetics, Silver Spring, MD, USA). A blinded investigator counted arterioles, inflammatory cells, and dermic appendages in ten fields per specimen $(x 20)$.

\section{Analysis of Vegf-a (angiogenesis), Nos2 (ischemia),} Icam-1 (cell adhesion), C5ar1 (complement system)

\section{RNA isolation}

Skin samples maceration was performed with a tissue Lyser $\mathrm{LT}^{\circledast}$ (Qiagen, Hilden, Germany). The products were microcentrifuged $(10,000 \times \mathrm{g})$ with $1 \mathrm{~mL}$ of Trizol ${ }^{\circledR}$ (Invitrogen, Carlsbad, CA, United States) and stainless-steel beads. Fragmentation was performed for $6 \mathrm{~min}$ at $50 \mathrm{~Hz}$.

After removal of the beads, $0.2 \mathrm{~mL}$ of chloroform (Merck, Whitehouse Station, NJ, United States) was added. The samples were centrifuged for $15 \mathrm{~min}$ at $10,000 \times \mathrm{g}$ and $4^{\circ} \mathrm{C}$. The aqueous phase was then transferred to a new microcentrifuge tube, and $0.5 \mathrm{~mL}$ of ice-cold isopropanol (Merck) was added to precipitate the RNA. Samples were incubated for $10 \mathrm{~min}$ and then centrifuged at $10,000 \times \mathrm{g}$ for $10 \mathrm{~min}$ at $4^{\circ} \mathrm{C}$. The supernatant was discarded, and the precipitated RNA washed with $1 \mathrm{~mL}$ of $75 \%$ ethanol. The RNA was then centrifuged for $5 \mathrm{~min}$ at $10,000 \times \mathrm{g}$ and $4^{\circ} \mathrm{C}$. The RNA pellet was resuspended in 50-100 $\mu \mathrm{L}$ of DNase/RNase-free sterile ultrapure water (Invitrogen).

The concentration of extracted RNA was determined using a NanoDrop ${ }^{\mathrm{TM}}$ ND-1000 spectrophotometer (Thermo Fisher Scientific, Waltham, MA, United States). Purity was evaluated by the absorbance ratio at $260 / 280 \mathrm{~nm}$, using only the RNAs whose ratios were $\geq 1.8$. To analyze RNA integrity, agarose gel electrophoresis was performed to verify the $28 \mathrm{~S}$ and $18 \mathrm{~S}$ bands. The extracted RNAs were stored at $-80^{\circ} \mathrm{C}$.

\section{cDNA synthesis}

A high-capacity RNA-to-cDNA kit (Applied Biosystems, Foster City, CA, USA) and GeneAmp 2400 thermocycler (Applied Biosystems) were used for the synthesis of cDNA from total RNA. For reaction and inactivation of this reaction, the tubes were incubated at $37^{\circ} \mathrm{C}$ for $60 \mathrm{~min}$ and at $95^{\circ} \mathrm{C}$ for $5 \mathrm{~min}$, respectively. The CDNA samples were stored at $-20^{\circ} \mathrm{C}$ until use. 


\section{Reverse transcription semi-quantitative polymerase chain reaction}

Analysis of mRNA expression of the genes of interest was performed by reverse transcription semi-quantitative polymerase chain reaction (qRT-PCR) in a StepOnePlus ${ }^{\mathrm{TM}}$ thermocycler (Applied Biosystems) with the TaqMan ${ }^{\circledR}$ gene expression assay system (Applied Biosystems). The probes and primers for the genes (rats) C5ar1 (Rn02134203_s1), Icam1 (Rn00564227_m1), Nos2 (Rn 00561646_m1), and Vegf-a (Rn01511602_m1) and for the endogenous control Actb (Rn 00667869_m1) were purchased from Applied Biosystems. qRT-PCR was performed in duplicate for each sample using $10 \mu \mathrm{L}$ TaqMan ${ }^{\circledR}$ Universal Master Mix II 2X, $1 \mu \mathrm{L} \mathrm{TaqMan}{ }^{\circledR}$ Gene Expression Assay $20 x$, and $4-\mu \mathrm{L}$ diluted cDNA (1:5 dilution) for a final volume of $20 \mu \mathrm{L}$ in 96-well plates coated with optical sealant. The reaction conditions were $50^{\circ} \mathrm{C}$ for $2 \mathrm{~min}, 95^{\circ} \mathrm{C}$ for $10 \mathrm{~min}, 40$ cycles at $95^{\circ} \mathrm{C}$ for $15 \mathrm{~s}$, and $60^{\circ} \mathrm{C}$ for $1 \mathrm{~min}$.

The expression level of each target gene was calculated by GenEx Standard 6.1 (MultiD Analyses AB, Göteborg, Sweden), which uses the $2^{-\Delta} \mathrm{Ct}$ method for relative quantification, in which:

$\mathrm{Ct}$ (threshold cycle) $=$ the point at which amplification reaches the logarithmic phase;

$\Delta \mathrm{Ct}=$ the difference in expression between the target gene and endogenous control of a given sample;

$\Delta \Delta \mathrm{Ct}$ = the difference between the $\Delta \mathrm{Ct}$ of the sample and the $\Delta \mathrm{Ct}$ of the control.

\section{Statistical analysis}

Nonparametric variables are shown as medians and interquartile ranges. Multiple groups were compared using Kruskal-Wallis test. When comparison test had a significant $p$-value, pair-wise comparison was performed by Dunn's test. Because of the small sample size, a bootstrap test was performed to certify the significance of our outcomes between CG and ASC group. The Hedges' g statistic coefficient was used to calculate the effect size between the control and ASC groups. Analysis was performed in Stata v14 (StataCorp, College Station, TX, USA) with p-value and power thresholds of 5 and $80 \%$, respectively.

\section{Results}

\section{Analysis of the survival area, and survival area/ total area rate}

The survival area and ratio of survival to total area are shown in Table 1 and Fig. 2.

The comparison of survival area among the groups showed significant difference $(p=0.0008)$. Pair-wise comparison showed a similar effect regarding the survival area between the control and MG ( $420 \mathrm{~mm}^{2} v$ v. $301.8 \mathrm{~mm}^{2} ; \mathrm{p}=0.06$, respectively).

The ASC group showed a higher survival area compared to CG $\left(720 \mathrm{~mm}^{2}\right.$ vs. $\left.420 \mathrm{~mm}^{2}, \mathrm{p}=0.02\right)$.

The ASC treatment improved the survival area when compared to CG and MG groups ( $p<0.001)$. In summary, the treatment with ASC increase two-times the survival area when compared to CG and MG (Table 1).

We tested a bootstrap analysis of survival comparing the CG vs. the survival area of the ASC group ( $p<0.001$, $95 \%$ confidence interval $-95 \% \mathrm{Cl}-3.02$ to -0.99 ). The effect size with a coefficient of Hedges' $\mathrm{g}$ statistic was -2.01 .

The comparison of survival area/total area rate (S/TR) among the groups showed significant difference $(p=0.008)$. A post-hoc test showed an increase in the S/TR between the CG and ASC group ( $45 \%$ vs. $78 \%, p=0.003$, respectively) and between the MG group and ASC group (32\% vs. $78 \%$; $p<0.001$, respectively) (Table 1 ).

The comparison between $C G$ and MG, regarding S/TR, showed no difference $(p=0.052)$ (Table 1$)$.

Table 1 - The survival area and the ratio of survival to total area in all groups presented as medians and interquartile ranges.

\begin{tabular}{ccc} 
Group & $\begin{array}{c}\text { Survival area* }\left(\mathbf{m m}^{2}\right) \\
\text { Median (IQR) }\end{array}$ & $\begin{array}{c}\text { Rate SA/TA } \\
\text { Median (IQR) }\end{array}$ \\
\hline Control & 420.00 & 0.45 \\
Culture & $311.34-531.33)$ & $(0.26-0.63)$ \\
medium & $(229.92-341.22)$ & 0.32 \\
& 720.32 & $(0.20-0.36)$ \\
ASC & $(640.84-840.06)$ & 0.78 \\
& & $(0.66-1)$ \\
\hline
\end{tabular}

*CG vs. MG, $\mathrm{p}=0.06$; ASC group vs. $\mathrm{CG}, \mathrm{p}=0.02 ;$ ASC group vs. MG, $p<0.001 ;{ }^{* *} A S C$ group vs. CG, $p=0.003 ;$ MG vs. ASC group, $p<0.001$; SA/TA: survival area/total area; IQR: interquartile ranges; ASC: adipocyte-derived stem cell.

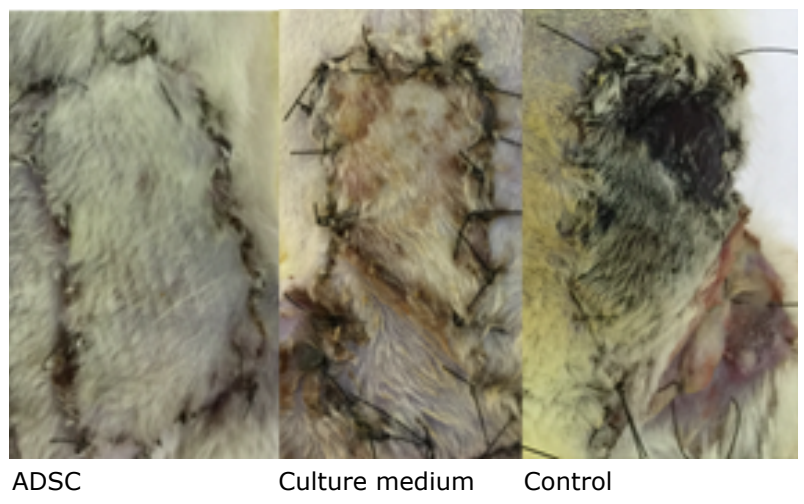

ASC: adipocyte-derived stem cell.

Figure $\mathbf{2}$ - The epigastric flap area on the seventh postoperative day. 


\section{Microscopic analysis}

The histology (H\&E) of the CG and MG distal flap area showed full-thickness skin necrosis, loss of dermic structure, subcutaneous edema, and a large number of infiltrated inflammatory cells in all those flaps that suffered $3 \mathrm{~h}$ of ischemia.

The ASC group showed less inflammatory cell infiltration, less subcutaneous edema, and more neoangiogenesis when compared to the other groups (Fig. 3).

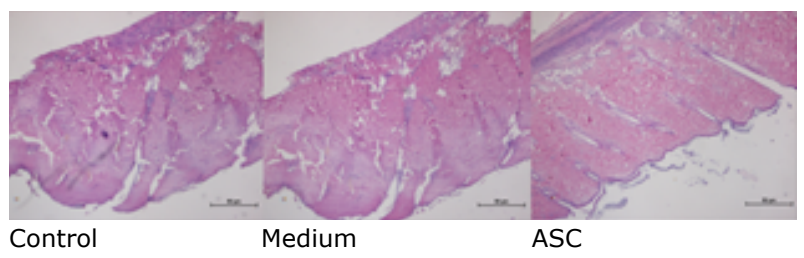

ASC: adipocyte-derived stem cell.

Figure 3 - Histologic analysis: control group, medium group, and ASC group (magnification of $\times 40$ ).

\section{Analysis of Vegf-a (angiogenesis), Nos2}

(ischemia), Icam-1 (cell adhesion), and C5ar1

(complement system)

There were significant differences in Vegf-a expression between all groups $(p=0.007)$.

A post-hoc analysis showed a 2.5 -fold increase in the Vegf-a expression in the ASC group vs. the CG ( 2.3 vs. $0.93, p=0.0008$, respectively). A similar result was observed when comparing Vegf-a expression in the ASC group vs. MG ( $p=0.03)$. This study showed similar results in Vegf-a expression between $C G$ and MG $(p=0.08)$ (Table 2).

Regarding Nos2 expression, there was a difference among the groups $(p=0.009)$. A post-hoc test showed a four-fold increase in Nos2 expression when comparing to the ASC group and the CG ( $p=0.03)$, as well as an increase in Nos2 expression between the MG and CG $(p=0.001)$, but no difference between ASC group and MG $(p=0.191)$.

There were no differences in Icam 1 expression among the groups $(p=0.06)$. Furthermore, there were significant differences in C5ar1 expression between all groups $(p=0.002)$. The pair-wise comparison showed $50 \%$ of decrease in C5ar1 expression in the ASC group vs. the CG $(p=0.02)$. A similar result was observed when comparing the MG and the ASC group $(p=0.05)$. There was no difference between $C G$ and MG $(p=0.143)$ (Table 2).
Table 2 - Median and interquartile ranges of Vegf-a, Nos2, Icam-1, and C5ar1 expression in all groups normalized to that of ACTB.

\begin{tabular}{ccccc}
\hline Group & $\begin{array}{c}\text { Vegf-a } \\
\text { Median } \\
(\mathbf{I Q R})\end{array}$ & $\begin{array}{c}\text { Nos2 } \\
\text { Median } \\
(\mathbf{I Q R})\end{array}$ & $\begin{array}{c}\text { Icam-1 } \\
\text { Median } \\
(\mathbf{I Q R})\end{array}$ & $\begin{array}{c}\text { C5ar1 } \\
\text { Median } \\
\text { (IQR) }\end{array}$ \\
\hline Control & 0.93 & 0.85 & 1.01 & 0.95 \\
$(0.8-1.1)$ & $(0.4-2.3)$ & $(0.8-1.3)$ & $(0.7-1.2)$ \\
Culture & 1.3 & 11.2 & 0.64 & 0.81 \\
medium & $(1.1-1.6)$ & $(3.5-53.0)$ & $(0.5-0.9)$ & $(0.5-1.2)$ \\
ASC & 2.3 & 3.4 & 0.93 & 0.5 \\
& $(1.9-2.8)$ & $(2.5-35.6)$ & $(0.8-1.6)$ & $(0.4-0.7)$ \\
\hline
\end{tabular}

Vegf-a: ASC group vs. the CG, $p=0.0008 ; A S C$ group vs. $M G, p=0.03$; Nos2: ASC group vs. CG, $p=0.03$; MG vs. CG, $p=0.001 ; C 5 r 1$ : ASC group vs. the $C G, p=0.02 ; M G$ vs. the $A S C$ group, $p=0.05$; IQR: interquartile ranges; ASC: adipocyte-derived stem cell.

\section{Discussion}

In the ASC group, we observed an increased survival area $\left(720 \mathrm{~mm}^{2}\right)$ when compared to the CG $\left(420 \mathrm{~mm}^{2}\right)$. In the ASC group, an increase of 1.8 times of the survival area/total area rate in the axial surgical flap when compared to the CG was also noticed. Similarly, Gao et al. ${ }^{12}$ showed an increase in the survival area in ASC group when compared to no treatment and MG in a random flap.

The flap survival depends on vascular regeneration. The histologic analysis showed an increase in vascular density and decreased inflammatory cells, edema, and necrosis in the ASC group compared to the control and culture medium group. These findings were similar to several authors' ones ${ }^{7,8}$. The literature data hypothesized the increase of survival ratio in the ASC group because of the paracrine effect of the stem cells ${ }^{8,16}$.

Moreover, the effect of ASC treatment might be analyzed in the different phases of the ischemia/ reperfusion phenomenon.

This study showed an increase in the VEGF-a levels in the ASC group compared with the control and medium groups. These findings were similar to the literature review by Foroglou et al. ${ }^{6}$ It showed an association of ASCs increased the vascular density and the surgical flap viability and cytokines (Vegf-a). In addition, Moritz et al. ${ }^{17}$ injected Vegf in surgical flaps submitted to ischemia-reperfusion and compared it with placebo. This experiment showed the positive effect of the Vegf-a cytokine on the viability of ischemic surgical flap ${ }^{10}$. Our results showed a four-fold increase in Nos2 levels in the ASC group compared with the control group (3.4vs. 0.85 , respectively, $\mathrm{p}=0.001$ ).

There was a discussion about the possible role of NO in tissue regeneration. Kane et $a{ }^{18} .^{18}$ analyzed ischemic surgical flaps in iNos knock-out mice, and discussed the 
role of iNos in the wound healing process. Initially, iNos was responsible for decease inflammation in the wound site, but the authors demonstrated iNos has a role in the angiogenesis phase. Therefore, a higher level of these biomarkers (Vegf-a and Nos2) could work in synergy and explain the increase in the survival area ${ }^{17}$.

Adhesion molecules (Icam-1 and Vcam-1) reflect the reperfusion phase of inflammatory reaction to ischemia in which leukocytes adhere to the endothelium, increasing vessel permeability, amplifying the inflammatory reaction by the migration of more inflammatory cells. We expected A lower Icam-1 expression in the ASC group. However, we found no differences in the Icam-1 levels among the groups. We did not find No other studies that evaluated the effect of ASC treatment in Icam-1 levels. Song et al. ${ }^{19}$ analyzed the effect of hyperbaric oxygen therapy on Icam-1 and Vcam-1 levels in the abdominal skin flap submitted to ischemia-reperfusion and showed reduction in the treatment group.

The last stage of $I R$ is the complement cascade activation. The cascade initiates by $\mathrm{C} 1 \mathrm{q}$, and the final product is C5. In this study, it was hypothesized that lower levels of complement in the ASC group could reflect the antiinflammatory effect of $\mathrm{ASC}^{20}$. In fact, the ASC treatment showed $50 \%$ of decreased in the C5ar1 levels when compared with the control group ( $0.5 \mathrm{vs}$. 0.95 , respectively, $\mathrm{p}=0.02$ ) and with the MG group ( 0.5 vs. 0.81 , respectively, $p=0.05$ ). We hypothesized it was thought the treatment of ASC in ischemia and reperfused flap could minimize the tissue and cellular damage by the inflammatory and immunological response.

This study has some limitations. The ideal animal model for flap studies is porcine, but we used a murine model due to the more manageable size of the rat and to the existing literature. Due to the lack of literature analyzing biomarkers in diabetes with IR, we selected several biomarkers that may not be useful tools for assessing flap survival were selected. Some studies have investigated other biomarkers such as superoxide dismutase, and catalase, but the results have been inconclusive ${ }^{21-23}$.

To solve the small sample size power limitation, the significance of these findings was confirmed testing bootstrap analysis. This statistical tool was used to confirm whether the calculated $p$-value remained significant $(p<0.001,95 \% \mathrm{Cl}-3.02$ to -0.99$)$. In an attempting to explain the mechanism of action of ASC therapy, we analyzed surrogate endpoints.

Several comorbidities such as diabetes, cardiovascular disease, and smoking can interfere in wound healing process. In a free flap transfer procedure, the surgeon can add more factors to interfere in the tissue regeneration. The idea to use an autologous strategy to improve tissue regeneration is attractive. In this study, we injected ASC immediately after the IR to minimize tissue necrosis.

While we adopted ASC as a regenerative strategy on the survival of axial flap in the present study, it is recognized that stromal vascular fraction (SVF) has been increasingly studied in this arena ${ }^{21-24}$. The SVF is apparently less costly and technically less complicated than $\mathrm{ASC}^{23,24}$. In addition, SVF seems to be more available worldwide compared with ASC. In this sense, a comparative study of ASC vs. SVF would be of interest ${ }^{22-24}$.

\section{Conclusion}

This study suggests that ASCs treatment increases the survival of axial flaps submitted to IR in diabetic rats.

\section{Author's contribution}

Scientific and intellectual content of the study: Camargo $\mathrm{CP}$, Harmsen MC and Gemperli R; Interpretation of data: Camargo CP, Kubrusly MS, Morais-Besteiro J, Harmsen MC and Gemperli R; Analysis of data: Kubrusly MS; Critical revision: Camargo CP, Morais-Besteiro J, Harmsen MC and Gemperli R.

\section{Data availability statement}

Data will be available upon request.

\section{Funding}

Fundação de Amparo a Pesquisa do Estado de São Paulo [https://doi.org/10.13039/501100001807]

Grant n 09290-2016

\section{Acknowledgments}

To thank all the people whose assistance was a milestone in the completion of this project: Mrs. Silvana Aparecida Biagion, Mrs. Edna Maria Rodrigues dos Santos, Mrs. Roqueline Alves Lago and Mr. Bruno Valério do Rosário.

\section{References}

1. Pang $Y$, Lineaweaver WC, Lei MP, Oswald T, Shamburger S, Cai Z, Zhang F. Evaluation of the mechanism of vascular endothelial growth factor improvement of ischemic flap survival in rats. Plast Reconstr Surg. 2003;112,(2):556-64. https://doi.org/10.1097/01. PRS.0000070965.28811.2C

2. Camargo $\mathrm{CP}$, Jacomo $\mathrm{AL}$, Battlehner $\mathrm{CN}$, Lemos $\mathrm{M}$, Saldiva $\mathrm{PH}$, Martins MA, Munhoz AM, Gemperli R. Botulinum toxin type $A$ on cutaneous flap survival in diabetic and tobaccoexposed rats. Acta Cir Bras. 2015;30(9):639-45. https://doi. org/10.1590/S0102-865020150090000009 
3. Zhang T, Gong W, Li Z, Yang S, Zhang K, Yin D, Xu P, Jia T. Efficacy of hyperbaric oxygen on survival of random pattern skin flap in diabetic rats. Undersea Hyperb Med. 2007;34:335-9.

4. Lu F, Mizuno H, Uysal CA, Cai X, Ogawa R, Hyakusoku H. Improved survival of random pattern skin aps through the use of adipose-derived stem cells. Plast Reconstr Surg. 2008;121(1):50-8. https://doi.org/10.1097/01. prs.0000293876.10700.b8

5. Muhammad KM, Abas WABW, Kah HK, Pingguan-Murphy $B$, Zain NM, Akram, $\mathrm{H}$. In vitro comparative study of white and dark polycaprolactone trifumarate in situ crosslinkable scaffolds seeded with rat bone marrow stromal cells. Clinics. 2012;67(6):629-38. https://doi.org/10.6061/ clinics/2012(06)14

6. Foroglou P, Karathanasis V, Demiri E, Koliakos G, Papadakis $M$. Role of adipose-derived stromal cells in pedicle skin flap survival in experimental animal models. World J Stem Cells. 2016;8(3):101-5. https://doi.org/10.4252/wjsc.v8.i3.101

7. Reichenberger MA, Heimer S, Schaefer A, Lass $U$, Gebhard MM, Germann G, Leimer U, Kollensperger E, Mueller W. Adipose derived stem cells protect skin flaps against ischemiareperfusion injury. Stem Cel Rev. 2012;8(3):854-62. https:// doi.org/10.1007/s12015-012-9368-5

8. Gao W, Qiao X, Ma S, Cui L. Adipose-derived stem cells accelerate neovascularization in ischaemic diabetic skin flap via expression of hypoxia-inducible factor- $1 \alpha \mathrm{J}$ Cell Mol Med. 2011;15(12):2575-85. https://doi.org/10.1111/ j.1582-4934.2011.01313.x

9. Peng $Z$, Yang $X$, Qin J, Ye $K$, Wang $X$, Shi $H$, Jiang $M$, Liu X, Lu X. Glyoxalase-1 Overexpression reverses defective proangiogenic function of diabetic adiposederived stem cells in streptozotocin-induced diabetic mice model of critical limb ischemia. Stem Cells Transl Med. 2016;6(1):261-71. https://doi.org/10.5966/ sctm.2015-0380

10. Varkarakis G, Daniels J, Coker K, Oswald T, Scheich A, Muskett A, Akdemir O, Lineaweaver W. Effects of comorbidities and implant reinforcement on outcomes after component reconstruction of the abdominal wall. Ann Plast Surg. 2010;64:595-7. https://doi.org/10.1097/ sap.0b013e3181da95e7.

11. Frederick JW, Sweeny L, Carroll WL, Peters GE, Rosenthal $E L$. Outcomes in head and neck reconstruction by surgical site and donor site. Laryngoscope. 2013;123:1612-7. https://doi.org/10.1002/lary.23775

12. Zahiri HR, Lumpkins K, Kelishadi SS, Zhu Y, Medina D, CondéGreen A, Silverman RP, Slezak S, Goldberg NH, Holton LH3rd, Sing DP. Significant predictors of complications after sternal wound reconstruction. A 21-year experience. Ann Plast Surg. 2012;69(4):439-41. https://doi.org/10.1097/ SAP.0b013e318231d1ef

13. Shi Y, Vanhoutte PM. Macro- and microvascular endothelial dysfunction in diabetes. J Diabetes. 2017;9(5):434-49. https://doi.org/10.1111/1753-0407.12521.PMID: 28044409
14. Bourin P, Bunnell BA, Casteilla L, Dominici M, Katz AJ, March KL, Redl H, Rubin JP, Yoshimura K, Gimble JM. Stromal cells from the adipose tissue-derived stromal vascular fraction and culture expanded adipose tissue-derived stromal/stem cells: a joint statement of the International Federation for Adipose Therapeutics and Science (IFATS) and the International Society for Cellular Therapy (ISCT). Cytotherapy. 2013;15(6):641-8. https://doi.org/10.1016/j. jcyt.2013.02.006.

15. Schneider CA, Rasband WS, Eliceiri KW. NIH Image to ImageJ: 25 years of image analysis. Nat Methods. 2012;9:671-5.

16. Uysal AC, Mizuno H, Ogawa R, Hyakusoku H. The effect of adipose-derived stem cells on ischemia-reperfusion injury: immunohistochemical and ultrastructural evaluation. Plast Reconstr Surg. 2009;124(3):804-15. https://doi. org/0.1097/PRS.0b013e3181b17bb4.

17. Moritz M, Pfeifer S, Balmayor ER, Mittermayr R, Wolbank $S$, Redl Hvan Griensven M. VEGF released from a fibrin biomatrix increases VEGFR-2 expression and improves early outcome after ischemia-reperfusion injury. J Tissue Eng Regen Med. 2017;11(7):2153-63. https://doi. org/10.1002/term.2114

18. Kane AJ, Barker JE, Mitchell GM, Theile DRB, Romero R, Messina A, Stewart AG. Inducible nitric oxide synthase (Nos2) activity promotes ischaemic skin flap survival. Br J Pharmacol. 2011;132(8):1631-8. https://doi.org/10.1038/ sj.bjp.0703944

19. Song K, Zhang M, Liu Y, Wang $Y$, Ma X. The effect of hyperbaric oxygen preconditioning on the expression of ICAM-1, VCAM-1, NF-KB and flap survival rate during ischemia-reperfusion injury in rat abdominal skin flaps. Zhonghua Zheng Xing Wai Ke Za Zhi. 2016;32(3):203-7.

20. Gorsuch WB, Chrysanthou E, Schwaeble WJ, Stahl GL. The complement system in ischemia-reperfusion injuries. Immunobiology. 2012;217,1026-33. https://doi. org/10.1016/j.imbio.2012.07.024.

21. Kelahmetoglu O, Demir R, Okten G, Alpaslan Pinarli F, DiramanETheeffectofmesenchymalstemcellsand sildenafil on flap survival in perforator-based flaps for ischemia/ reperfusion injury: An experimental study. Microsurgery. 2106;36(5):402-9. https://doi.org/10.1002/micr.22396.

22. Bora P, Majumdar AS. Adipose tissue-derived stromal vascular fraction in regenerative medicine: a brief review on biology and translation. Stem Cell Res Ther. 2017;8(1):145. https://doi.org/10.1186/s13287-017-0598-y

23. Kim H, Kim Y, Park J, Hwang NS, Lee YK, Hwang Y. recent advances in engineered stem cell-derived cell sheets for tissue regeneration. Polymers (Basel). 2019;11(2):209. https://doi.org/10.3390/polym11020209

24. Spieman M, van Dongen JA, Willemsen JC, Hoppe DL, van der Lei B, Harmsen MC. The power of fat and its adiposederived stromal cells: emerging concepts for fibrotic scar treatment. J Tissue Eng Regen Med. 2017;11(11):3220-35. https://doi.org/0.1002/term.2213 